\title{
Endoscopic removal of buried lumen-apposing metal stents used for cystogastrostomy and cholecystogastrostomy
}

The Hot AXIOS system is a new device for transgastric or transduodenal endoscopic drainage of a pancreatic pseudocyst or the gallbladder [1,2] using a lumen-apposing metal stent (LAMS) mounted on an electrocautery-enhanced introduction system. The device seems to be relatively safe in expert hands; however, the literature on management of its complications is limited [1-4]. Hereby, we report on two patients with embedded LAMSs, which were endoscopically removed.

Patient 1 was a 68-year-old man with a pseudocyst after acute pancreatitis who underwent successful endoscopic ultrasound (EUS)-guided cystogastrostomy with placement of an AXIOS stent (10× $10 \mathrm{~mm}$ ). Endoscopic removal of the LAMS was planned 3 months later; however, gastroscopy showed tissue overgrowth at the gastric flange of the LAMS making direct removal of the stent with a rat-tooth forceps or snare impossible. To avoid the patient having to undergo surgery, we opted for endoscopic treatment consisting of forced argon plasma coagulation (APC), needle-knife incision, and dilation of the stent up to $12 \mathrm{~mm}$ ( Video 1 ). After the tissue overgrowth had been sufficiently removed from the gastric flange, it was possible to remove the LAMS with a rattooth forceps. No complications subsequently occurred.

Patient 2 was a 59-year-old man with acute acalculous cholecystitis who underwent successful endoscopic gallbladder drainage by EUS-guided cholecystogastrostomy using a $15 \times 10$-mm AXIOS stent. LAMS removal was performed after 4 months. At gastroscopy, we found a buried gastric flange of the LAMS ( $\bullet$ Fig. 1 ) in the antrum. Because standard stent removal with forceps was impossible, we dilated the LAMS up to $15 \mathrm{~mm}$ with a balloon, entered it with the endoscope, and removed the stent inside-out with a rat-tooth forceps. No complications subsequently occurred.

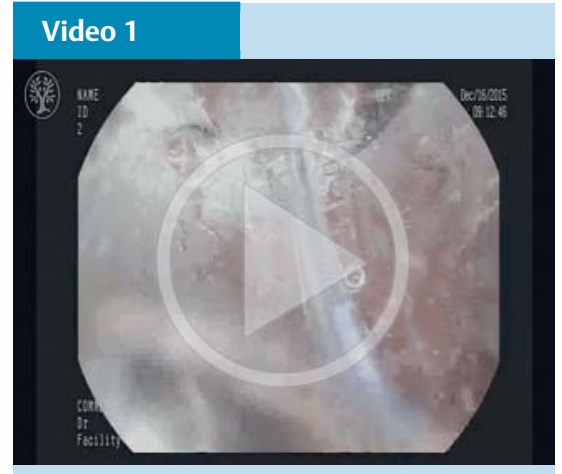

Endoscopic view of a lumen-apposing metal stent (LAMS) placed for cystogastrostomy with its gastric flange buried by tissue overgrowth being removed endoscopically using argon plasma coagulation (APC), needle-knife incision, dilation of the stent, and extraction with a rat-tooth forceps.

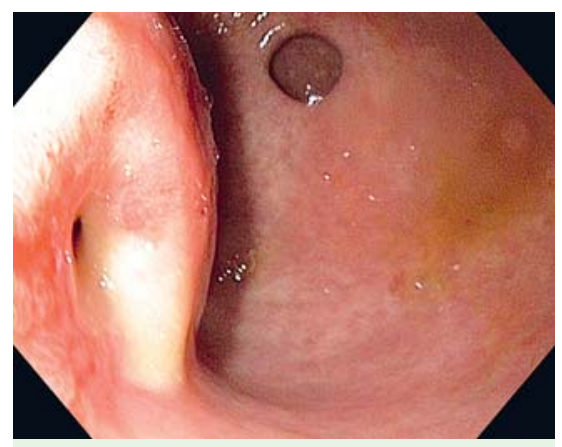

Fig. 1 Significant tissue overgrowth by gastric mucosa affecting a lumen-apposing metal stent (LAMS) after a stent dwell time of 4 months in a patient who had undergone cholecystogastrostomy.

Both these clinical cases show that tissue overgrowth at the gastric side of a LAMS can be a complication after cystogastrostomy and cholecystogastrostomy, making regular stent removal with a forceps impossible [1,3]. In such circumstances, endoscopic techniques as described above can be considered as rescue therapy.

Endoscopy_UCTN_Code_CPL_1AL_2AD
Competing interests: Frank P. Vleggaar is a consultant for Boston Scientific.

\section{Tom C. Seerden ${ }^{1}$, Frank P. Vleggaar ${ }^{2}$}

${ }^{1}$ Department of Gastroenterology and Hepatology, Amphia Hospital, Breda, The Netherlands

${ }^{2}$ Department of Gastroenterology and Hepatology, University Medical Center Utrecht, Utrecht, The Netherlands

\section{References}

1 Walter D, Teoh AY, Itoi $T$ et al. EUS-guided gall bladder drainage with a lumen-apposing metal stent: a prospective long-term evaluation. Gut 2016; 65: 6-8

2 Walter D, Will U, Sanchez-Yague A et al. A novel lumen-apposing metal stent for endoscopic ultrasound-guided drainage of pancreatic fluid collections: a prospective cohort study. Endoscopy 2015; 47: 63-67

3 Fabbri C, Luigiano C, Marsico $M$ et al. A rare adverse event resulting from the use of a lumen-apposing metal stent for drainage of a pancreatic fluid collection: "the buried stent”. Gastrointestinal Endosc 2015; 82: $585-587$

4 Shah R, Shah J, Waxman I et al. Safety and efficacy of endoscopic ultrasound-guided drainage of pancreatic fluid collections with lumen-apposing covered self-expanding metal stents. Clin Gastroenterol Hepatol 2015; 13: 747-752

Bibliography

Dol http://dx.doi.org/

10.1055/s-0042-107073

Endoscopy 2016; 48: E179

(c) Georg Thieme Verlag KG

Stuttgart · New York

ISSN 0013-726X

\section{Corresponding author}

\section{T. C. Seerden, MD}

Department of Gastroenterology and Hepatology Amphia Hospital

Molengracht 21

4818 CK Breda

The Netherlands

tseerden@amphia.nl 